\title{
Can Neutrophil-Lymphocyte Ratio and Platelet-Lymphocyte Ratio Be Related with Skeletal Muscle Mass Area in COPD Patients with Acute Exacerbation?
}

\author{
Akut Alevlenme Olan KOAH Hastalarında Nötrofil-Lenfosit Oranı ve \\ Trombosit-Lenfosit Oranı ile İskelet Kas Alanı Arasında İlişki Olabilir mi?
}

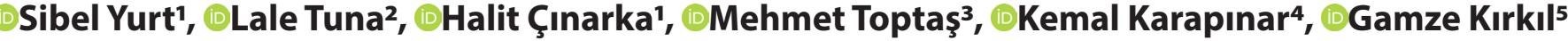 \\ 'University of Health Science, Yedikule Chest Disease and Chest Surgery Education and Research Hospital, Pulmonology Department, Istanbul, Turkey \\ 2University of Health Science, Yedikule Chest Disease and Chest Surgery Education and Research Hospital, Radiology Department, Istanbul, Turkey \\ ${ }^{3}$ University of Health Science, Yedikule Chest Disease and Chest Surgery Education and Research Hospital Turkey,Anesthegiology Department, Istanbul, Turkey \\ 4 University of Health Science, Yedikule Chest Disease and Chest Surgery Education and Research Hospital, Chest Surgery Department, Istanbul, Turkey \\ ${ }^{5}$ Firat University, Medical Faculty, Pulmonology Department, Elazığ, Turkey
}

\begin{abstract}
Introduction: This study was designed to assess whether there is a relation between inflammatory biomarkers such as NLR, PLR and psoas muscle area (PMA) as a marker of sarcopenia in COPD pateints who admitted to the emergency department of our clinic.

Material and Method: Retrospectivly one hundred forty three COPD patients who had CT scan for any reason during hospital admission were included. Patient characteristics and clinical and laboratory data were evaluated retrospectively.

Results: In our study, we performed the correlations between NLR, PLR and CRP, FEV1, FVC, FEV1/FVC, right PMA, left PMA, total PMA. NLR and PLR were positively correlated with CRP $(r=0.60, p<0.001$, $r=0.37, p<0.001$, respectively), and no correlation was observed between NLR, PLR, CRP and all PMA values. However, there was a positive correlation between all PMA values and FEV1, FEV1/FVC parameters. There was no correlation between sarcopenia and emergency admission frequency and mortality.

Conclusion: NLR, and PLR may have a role as a biomarker of inflammation in COPD and its exacerbation. Sarcopenia is an expected finding in COPD patients, but relation between sarcopenia and inflammation requires further investigation.
\end{abstract}

Keywords: Neutrophil-lymphocyte ratio, platelet-lymphocyte ratio, COPD, Sarcopenia
Öz

Giriş: Bu çalışma kliniğimizin acil servisine başvuran KOAH hastalarında sarkopeni belirteci olarak psoas kas alanı (PMA) ve nötrofil-lenfosit oranı ( NLO), trombosit-lenfosit oranı ( PLR) gibi inflamatuar biyobelirteçler arasında bir ilişki olup olmadığını değerlendirmek için tasarlanmıştır.

Gereç ve Yöntem: Retrospektif olarak daha önce hastaneye başvuru sırasında herhangi bir nedenle BT taraması yapılan $143 \mathrm{KOAH}$ hastas dahil edildi. Hasta özelikleri ile klinik ve laboratuvar verileri geriye dönük olarak değerlendirildi.

Bulgular: Çalışmamızda NLR, PLR ve CRP, FEV1, FVC, FEV1/FVC, sağ PMA, sol PMA, total PMA arasındaki korelasyonlara bakıldı. PLR, CRP ile pozitif korelasyon gösterdi (sırasıyla $r=0.60, p<0.001, r=0.37$, $\mathrm{p}<0.001$ ) ve NLR, PLR, CRP ve tüm PMA değerleri arasında korelasyon gözlenmedi. Bununla birlikte tüm PMA değerleri ile FEV1, FEV1/FVC parametreleri arasında pozitif bir korelasyon vardı. Sarkopeni ile acil basvuru sıklığı ve mortalite arasında bir ilişki yoktu.

Sonuç: NLR ve PLR, KOAH hastalarında beklenen bir bulgudur, ancak sarkopeni ve inflamasyon arasındaki ilişki daha fazla araştırma gerektirir.

Anahtar Kelimeler: Nötrofil-lenfosit oranı, trombosit-lenfosit oranı, $\mathrm{KOAH}$, Sarkopeni

Corresponding (iletişim): Sibel Yurt, University of Health Sciences, Yedikule Chest Disease and Chest Surgery Education and Research Hospital, Pulmonology Department, Istanbul, Turkey

E-mail (E-posta): yurtsibell@gmail.com

Received (Geliş Tarihi): 05.08.2020 Accepted (Kabul Tarihi): 11.09.2020 


\section{INTRODUCTION}

The clinical assessment of COPD patients is complicated by the presence of multi- morbid conditions. The extrapulmonary manifestations are increasingly recognised as important contributors to functional decline in patients with COPD. [1] Functional impairment is one of these extrapulmonary manifestations that is associated with muscle weakness and body weight loss and it is well known that patients with COPD suffer from loss of muscle mass. ${ }^{[2-4]}$

Sarcopenia describes age-related loss of skeletal muscle, which leads to increased risk of physical disability, poor health status and death. ${ }^{[5]}$ Sarcopenia is increasingly recognised as a clinical syndrome with multiple contributing factors, including physical inactivity, malnutrition and chronic disease. Since COPD, in some respects, is considered a disease of accelerated ageing, one would hypothesise that sarcopenia would be relevant to patients with COPD. Recently, it was shown that the overall prevalence of sarcopenia in COPD was $14.5 \%{ }^{[6]}$ The European Working Group on Sarcopenia in Older People (EWGSOP) developed practical clinical diagnostic criteria for sarcopenia. ${ }^{[5]}$ Though the term has been used loosely in COPD, data on consensus-defined sarcopenia are lacking, but are necessary to understand the size and nature of this problem in a disease characterised by differential muscle atrophy and weakness.

It is also well-known that COPD is characterised by systemic inflammation. There are variable parameters that are used to evaluate the degree of this inflammation. In recent years, the neutrophil-lymphocyte ratio (NLR) and platelet-lymphocyte ratio (PLR) have emerged as useful, inexpensive and easily performed biomarkers to predict systemic inflammation. ${ }^{[7-9]}$ Many studies have shown that NLR as well as PLR, are positively associated with inflammation. ${ }^{[10-11]}$ Moreover, it was shown that during acute exacerbations of COPD, NLR increased when compared with stable period. And the authors concluded that NLR might be used as an easily measurable, available and cost-effective parameter with high prognostic accuracy in clinical practice. ${ }^{[12]}$

We hypothesized that NLR and PLR can be related with skeletal mass loss, as inflammation may cause malnutrition status, and sarcopenia may be a good indicator of malnutrition. This study was designed to assess whether there is a relation between inflammatory biomarkers such as NLR, PLR and psoas muscle area (PMA) as a marker of sarcopenia in COPD pateints who admitted to the emergency department of our clinic.

\section{MATERIAL AND METHOD}

Patients diagnosed with COPD according to Global Initiative for Chronic Obstructive Pulmonary Disease (GOLD) guidelines (FEV1 $<80 \%$ predicted, FEV1/FVC $<70 \%$ and bronchodilatation effect $<12 \%)^{[13]}$ and admitted because of an acute attack were recruited from Emergency Department of Yedikule Chest Diseases and Thoracic Surgery Training and Research Hospital between January 2016 and May 2018. Acute exacerbationCOPD was defined as a history of increased breathlessness and at least two of the following symptoms for $24 \mathrm{~h}$ or more: increased cough frequency or severity, sputum volume or purulence and wheeze. ${ }^{[14]}$

One hundred fortythree COPD patients who had CT scan for any reason during hospital admission were included. Patients who had acute or chronic infection, hematologic disorders, various malignancies, acute poisoning, thrombus formation, diabetic nephropathy, or treatment with corticosteroids or immunosuppressants were excluded from the study.

Patient characteristics and clinical and laboratory data were evaluated retrospectively for each patient included age and sex, C-reactive protein (CRP), white blood cells (WBC), hemoglobin $(\mathrm{Hb})$, hematocrit $(\mathrm{Htc})$, neutrophil, platelet, lymphocyte count. The absolute neutrophil count divided by the absolute lymphocyte count was regarded as neutrophil to lymphocyte ratio (NLR), and the absolute platelet count divided by the absolute lymphocyte count was platelet to neutrophil ratio (PLR).

Spirometric examination was conducted according to the European Respiratory Society (ERS) criteria. Forced expiratory volume in 1 second (FEV1) and forced vital capacity (FVC) are expressed as percentages of predicted values according to the prediction equations of the ERS. ${ }^{[15]}$

CT scan images were used to determine the quantity of skeletal muscle. CT images obtained from 128-slice spiral CT (Ingenuity Elite model, Philips, Holland), and it has $2 \mathrm{~mm}$ section thickness. The skeletal muscle cross-sectional area $\left(\mathrm{cm}^{2}\right)$ was manually measured at the caudal end of the third lumbar vertebra. Computed tomography images were used to determine the quantity of skeletal muscle. CT scans were retrieved to measure right and left PMA, to obtain the total PMA. The PMA was measured by an observer who was blinded to the outcome and disease severity. The frequency of emergency admission of patients in the next year was recorded.

The study was approved by the institutional ethical board.

\section{Statistical analysis}

Data statistics were performed using SPSS 21.0 (SPSS for Windows, ver. 21.0). The normality of data distribution was checked by the Kolmogorov-Smirnov test. Quantitative variables were presented as mean \pm SD, and categorical variables were expressed as percentages. The relationships between continuous variables were computed via Pearson correlation coefficient. A 2-tailed $\mathrm{p}<0.05$ was considered as statistical significance.

\section{RESULTS}

A total of 143 COPD patients were included in the study. The mean age was $62.69 \pm 2.64(32-90)$ years. Of the 143 COPD patients, 91 (63.63\%) were men and 52 (36.36\%) were women. The laboratory measurements and pulmonary function test results of patients are summarized in Table 1 . We had no control group for comparing the laboratory parameters, but when we search normal ranges of these parameters we saw that NLR was increased (normal value can be accepted as 1.4) and also PLR was increased (normal value can be accepted as 113.42). 
Although median neutrophil count was between normal range, $21 \%$ of patients had increased numbers of neutrophil.

\begin{tabular}{|c|c|}
\hline Parameter & Mean \pm SD \\
\hline WBC $\left(10^{3} \mu / L\right)$ & $8.93 \pm 3.56$ \\
\hline $\mathrm{Hb}(\mathrm{g} / \mathrm{dL})$ & $12.77 \pm 2.08$ \\
\hline $\mathrm{Htc}(\%)$ & $38.78 \pm 5.82$ \\
\hline Neutrophil $\left(10^{3} \mu / \mathrm{L}\right)$ & $6.68 \pm 5.44$ \\
\hline Lymphocyte $\left(10^{3} \mu / \mathrm{L}\right)$ & $2.14 \pm 0.94$ \\
\hline Platelet $\left(10^{3} \mu / L\right)$ & $273.76 \pm 117.61$ \\
\hline Neutrophil /Lymphocyte ratio (NLR) & $3.96 \pm 3.88$ \\
\hline Platelet/Lymphocyte ratio (PLR) & $150.67 \pm 92.31$ \\
\hline $\mathrm{CRP}(\mathrm{mg} / \mathrm{L})$ & $33.59 \pm 55.90$ \\
\hline FEV1 (pred\%) & $65.14 \pm 13.36$ \\
\hline FVC (pred\%) & $92.66 \pm 15.94$ \\
\hline FEV1/FVC & $69.25 \pm 5.70$ \\
\hline
\end{tabular}

When we grouped patients according to COPD stage; 10 patients were stage IV (FEV1 $<30 \%), 20$ patients were stage III $(\leq 30 \% \mathrm{FEV} 1<50), 111$ patients were stage II $(\leq 50 \% \mathrm{FEV} 1<80)$, and 10 pateints were stage I (FEV1 $\geq 80 \%$ ).

Mean PMA was calculated as 15.01 (cut-off $<16.8$ for sarcopenia) in our patients Psoas muscle area of patients are shown on Table 2.

\begin{tabular}{lc}
\hline Table 2. Psoas muscle area of patients & \\
\hline Parameter & Mean \pm SD \\
\hline Right psoas muscle area $\left(\mathrm{cm}^{2}\right)$ & $7.67 \pm 2.68$ \\
Left psoas muscle area $\left(\mathrm{cm}^{2}\right)$ & $7.34 \pm 2.52$ \\
Total psoas muscle area $\left(\mathrm{cm}^{2}\right)$ & $15.01 \pm 5.07$ \\
\hline
\end{tabular}

In our study, we performed the correlations between NLR, PLR and CRP, FEV1, FVC, FEV1/FVC, right PMA, left PMA, total PMA. NLR and PLR were positively correlated with CRP ( $r=0.60$, $p<0.001, r=0.37, p<0.001$, respectively), and no correlation was observed between NLR, PLR, CRP and all PMA values. However, there was a positive correlation between all PMA values and FEV1, FEV1/FVC parameters (Table 3).

\begin{tabular}{llll}
\hline & \multicolumn{3}{l}{$\begin{array}{l}\text { Table 3. Correlation between all PMA and FEV1, FEV1/FVC, NLR, PLR, CRP } \\
\text { values }\end{array}$} \\
\hline & Right PMA & Left PMA & Total PMA \\
\hline FEV1 & $0.295(0.01)$ & $0.234(0.043)$ & $0.273(0.018)$ \\
FEV1/FVC & $0.322(0.005)$ & $0.303(0.008)$ & $0.322(0.005)$ \\
NLR & $-0.052(0.54)$ & $0.023(0.78)$ & $-0.016(0.84)$ \\
PLR & $-0.150(0.075)$ & $-0.100(0.235)$ & $-0.129(0.125)$ \\
CRP & $-0.04(0.635)$ & $0.018(0.834)$ & $-0.012(0.883)$ \\
\hline Values are R (p value) & & & \\
\hline
\end{tabular}

There was no correlation between sarcopenia and emergency admission frequency and mortality.

\section{DISCUSSION}

This study was designed to assess whether there is a relation between inflammatory biomarkers such as NLR, PLR and PMA as a marker of sarcopenia in COPD pateints. Although we were not able to show any relation between NLR, PLR and PMA, a positive correlation between pulmonary function parameters and PMA was determined. In this cohort study, NLR and PLR levels increased in COPD patients, and both NLR, and PLR were positively correlated with CRP. But no correlation was present between all PMA values and NLR, PLR, and CRP. Therefore, we conclude that increased NLR and PLR can not be accepted as significant predictors for sarcopenia in COPD patients, and PMA levels may predict disease stage according to the pulmonary function parameters.

The pathogenesis of COPD is complex. It is generally accepted that inflammatory response associated with prolonged exposure to noxious gases plays an important role, and pulmonary inflammatory response is accompanied by systemic inflammatory response. ${ }^{[16]}$ Inflammation in COPD is amplified during exacerbation episodes in comparison with stable periods and increased levels of inflammatory markers that are associated with lung function decline. ${ }^{[17]}$ The cytokines and chemokines amplify the immune response and play significant roles in the pathogenesis of COPD. Neutrophils and platelets are responsible for the production of cytokines and chemokines, which in turn contribute to the activation of these neutrophils and platelets. ${ }^{[18]}$ It is well-known that systemic inflammation is reflected by an increased number of neutrophil granulocytes in the circulation, and neutrophil granulocyte count is associated with progression of COPD. [19] The reason for the development of neutrophilocytosis in patients with COPD is not fully understood, but it is hypothesized to be a result of "over-spill" from the airway inflammation that characterizes COPD. ${ }^{16]}$ In our study, although median neutrophil count was between normal range, $21 \%$ of patients had increased numbers of neutrophil.

Recently, neutrophil to lymphocyte ratio has attracted attention as an inflammatory biomarker. Previous studies have shown that NLR is a cost-effective, rapid, and reliable marker of inflammation, and positively correlated with other inflammatory markers such as CRP and ESR to predict inflammation in autoimmune diseases. ${ }^{[20,21]}$ It has also been proven that NLR increased in COPD patients. ${ }^{[22]}$ Moreover, in another study, authors showed that NLR was significantly higher in patients with COPD exacerbation than in controls and individuals with stable COPD (exacerbation, stable COPD, control values were 12.4, 2.4, and 1.4, respectively). ${ }^{[23]}$ In the same study, it was determined that BODE index, mMRC, and the 6MWT were significantly correlated with NLR. We were able to show a positive correlation between NLR and CRP values. Previously, Gan et al. ${ }^{[24]}$ reported that various systemic inflammatory markers including C-reactive protein (CRP) were elevated in patients with COPD. Also, it was shown that CRP was the most reliable biomarker for confirming COPD 
exacerbation. ${ }^{[25]}$ So it is not a surprising finding to determine a relation between NLR and CRP values. Taylan et al. ${ }^{[26]}$ also found positive correlation between CRP and NLR values, and they demonstrated that an optimal cut-off value of 3.29 for NLR can be used to identify patients with AE-COPD.

The platelet-lymphocyte ratio (PLR) is also accepted as a novel marker in many systemic inflammatory disorders. ${ }^{[27]}$ Platelet activation is observed in patients with COPD and AECOPD, and represents a novel pathological mechanism in COPD. ${ }^{[28]}$ It was proven previously that PLR levels were significantly higher in patients with AECOPD compared to those with stable COPD. [12]

Yao et al. ${ }^{[29]}$ reported that NLR and PLR levels were higher in non-survivors than in survivors who were patients with AECOPD, and the NLR played a valuable role in predicting the in-hospital mortality of patients with AECOPD. Moreover, at a cut-off value of 182.68 , the sensitivity and specificity of the PLR in predicting hospital mortality were $64.86 \%$ and $58.27 \%$, respectively, which suggests a lower predictive accuracy than with the NLR. In addition, the correlation between the PLR and CRP is not linear $(r=0.219)$.

Recently, it is shown that normal range of NLR and PLR is 2.18 , and 113.42 , respectively. ${ }^{[27]}$ So, we used these ranges to compare our results. As shown on table 1, our patients NLR and PLR values were higher than normal ranges (3.96 vs 2.18, 150.67 vs 113.42). It is not a surprising finding, because both these parameters are known as inflammatory biomarkers, and as COPD is a systemic inflammatory disease, it will be expected that these parameters will be increased in these patients.

Sarcopenia was first defined as primary sarcopenia characterized by decreased muscle mass in the elderly. [30] The prevalence of sarcopenia generally ranges between $6-22 \%$ over the age of 65 years. ${ }^{\left[{ }^{11]}\right.}$ Secondary sarcopenia is defined by three main pathogenic mechanisms; inflammatory activity, malnutrition and physical activity disorder. Catabolic inflammatory processes often observed in chronic illnesses can enhance sarcopenia. As COPD patients are generally over the age of 65 years, and as the presence of systemic inflammation strongly affects quality of life, leads to weight loss, muscle wasting and tissue depletion in COPD patients, one can expect that sarcopenia can be detected in these patients. ${ }^{[32]}$ Computed tomography (CT) and magnetic resonance imaging (MRI) are the gold standards for muscle mass assessment. ${ }^{[5]}$ In this study, total PMA was measured in preference to the total abdominal muscle area, because PMA is the core muscle that reflects the condition of skeletal muscle in the whole body. PMA measurement could be performed manually by tracing around the left and right psoas muscle after a short training period. Measurement of total PMA was reported as reproducible in previous studies, because no intraobserver and interobserver differences was observed. The method is feasible using most standard PACS viewers, so there is no need for any additional resources, and is representative of likely clinical application. So, we prefered to calculate PMA in our cohort for determining the relation between inflammation and COPD stage. Mean PMA was calculated as 15.01 (cut-off $<16.8$ for sarcopenia) in our patients. ${ }^{[33]}$

In the COPD population the prevalence of sarcopenia is reported to be between $20 \%-40 \% \cdot{ }^{[6,34,35]}$ Byun et al. ${ }^{[36]}$ reported that COPD patients with sarcopenia tended to be older, have a higher percentage of cardiovascular comorbidity, more severe mMRC dyspnea scores, higher BODE index scores, and lower exercise tolerance in the 6MWD than those without sarcopenia. In the same study, authors showed that the presence of sarcopenia was highly associated with levels of systemic inflammation, however, COPD severity was not associated with the presence or absence of sarcopenia. Another syudy showed that loss of muscle mass and muscle strength could be greater in patients with moderate-to severe COPD or during acute COPD exacerbations. ${ }^{[37-39]}$ Severity of COPD, and severity of dyspnoea were the main clinical outcomes associated with sarcopenia in COPD patients. ${ }^{[40]}$ COPD patients with sarcopenia had lower FEV1, lower exercise capacity and lower physical activity than patients without sarcopenia. ${ }^{[6]}$ We also showed that COPD severity was positively correlated with PMA values.

Lin et al. ${ }^{[41]}$ designed a study to demonstrate the relationship between sarcopenia and systemic inflammatory response (neutrophil/lymphocyte ratio, platelet/lymphocyte ratio, and large platelet/lymphocyte ratio [LPLR]) prior to radical gastrectomy for gastric cancer. They found that NLR and PLR elevated in half of the sarcopenia patients (57.7\%). The authors conclude that using PLR as primary screening test (a sensitivity of $91.3 \%$ ) aids with the early, simple, and convenient identification of sarcopenia, which may facilitate the use of therapeutic intervention to ensure a successful perioperative management and postoperative rehabilitation, a high quality of life, and a longer likelihood of survival. Similiar finding that inflammation is associated with sarcopenia is consistent with a well-established prior literature on non-metastatic colon carcinoma. ${ }^{[42]}$ We were not able to show any correlation between NLR, PLR and PMA values.

Measurements of lung function, specifically forced expiratory volume in $1 \mathrm{~s}$ (FEV1), are the most widely known traditional markers to assess COPD severity. However, these measurements correlate poorly with the presence of some symptoms and may not reliably reflect the intensity of inflammatory status. ${ }^{[43,44]}$ We were not able to show any correlation between FEV1 and NLR, PLR values. The statistical power of our study may not have been sufficient to detect such associations.

Our study has several limitations. Firstly, we were unable to disentangle the network of two-way relationships among inflammation, and sarcopenia. Further research is needed to address this issue. Secondly, this was a single institution study. A multicenter prospective study including other regions is essential to overcome this limitation and broaden the generalizability of the study results. 


\section{CONCLUSION}

NLR, and PLR may have a role as a biomarker of inflammation in COPD and its exacerbation. Sarcopenia is an expected finding in COPD patients, but relation between sarcopenia and inflammation requires further investigation.

\section{ETHICAL DECLARATIONS}

Ethics Committee Approval: The study was carried out with the permission of University of Health Sciences, Istanbul Training and Research Hospital Clinical Research Ethics Committee (Date: 21.12.2018, number: 1595).

Informed Consent: Because the study was designed retrospectively, no written informed consent form was obtained from patients.

\section{Referee Evaluation Process: Externally peer-reviewed.}

Conflict of Interest Statement: The authors have no conflicts of interest to declare.

Financial Disclosure: The authors declared that this study has received no financial support.

Author Contributions: All of the authors declare that they have all participated in the design, execution, and analysis of the paper, and that they have approved the final version.

\section{REFERENCES}

1. Houben-Wilke S, Augustin IM,Vercoulen JH, et al. COPD stands for complex obstructive pulmonary disease. Eur Respir Rev 2018;27(148):180027.

2. Agusti A, Soriano JB. COPD as a systemic disease. COPD 2008;5:133-8.

3. Rabe KF, Watz H. Chronic obstructive pulmonary disease. Lancet 2017;389:1931-40.

4. Hwang JA, Kim YS, Leem AY, et al. Clinical implications of sarcopenia on decreased bone density in men with COPD. Chest 2017;151:1018-27.

5. Cruz-Jentoft AJ, Baeyens JP, Bauer JM, et al. Sarcopenia:European consensus on definition and diagnosis:Report of the European Working Group on Sarcopenia in Older People. Age Ageing 2010;39:412-23.

6. Jones SE, Maddocks M, Kon SSC, et al. Sarcopenia in COPD:prevalence, clinical correlates and response to pulmonary rehabilitation. Thorax 2015;70:213-8.

7. Zahorec R. Ratio of neutrophil to lymphocyte counts-rapid and simple parameter of systemic inflammation and stress in critically ill. Bratisl Lek Listy 2001;102:5-14.

8. Sertoglu E, Uyanik M. Accurate use of neutrophil/lymphocyte ratio from the perspective of laboratory experts. Vasc Health Risk Manag 2014;10:134.

9. Ozgonul C, Sertoglu E. Accurate use of neutrophil/lymphocyte ratio in patients with age-related macular degeneration. Ocul Immunol 2015;1-2.

10. Imtiaz F, Shafique K, Mirza SS, Ayoob Z, Vart P, Rao S. Neutrophil Lymphocyte Ratio as a Measure of Systemic Inflammation in Prevalent Chronic Diseases in Asian Population. Int Arch Med 2012;5(1):2.

11. Templeton AJ, McNamara MG, Seruga B, et al. Prognostic Role of Neutrophil-To- Lymphocyte Ratio in Solid Tumors:A Systematic Review and Meta-Analysis. J Natl Cancer Inst 2014;106(6):dju124.

12. Kurtipek E, Bekci TT, Kesli R, Erdem SS, Terzi Y. The role of neutrophillymphocyte ratio and platelet-lymphocyte ratio in exacerbation of chronic obstructive pulmonary disease. J Pak Med Assoc 2015;65:1283.

13. https://goldcopd.org/wpcontent/uploads/2018/11/GOLD-2019POCKET-GUIDE-FINAL_WMS.pdf
14. Hurst JR, Wedzicha JA. Chronic obstructive pulmonary dis-ease:the clinical management of an acute exacerbation. Postgrad Med J 2004;80(947):497-505.

15. Standardized lung function testing. European Community for Steel and Coal, Official Statement of the European Respiratory Society. Eur Respir J 1993;6(16):5-40.

16. Sinden NJ, Stockley RA. Systemic inflammation and comorbidity in COPD:a result of 'overspill' of inflammatory mediators from the lungs? Review of the evidence. Thorax 2010;65(10):930-6.

17. Wedzicha JA, Donaldson GC. Exacerbations of chronic obstructive pulmonary disease. Respir Care 2003;48(12):1204-13.

18. Jaillon S, Galdiero MR, Del Prete D, et al. Neutrophils in innate and adaptive immunity. Semin Immunopathol 2013;35 (4):377-94.

19. Hogg JC, Chu F, Utokaparch S, et al. The nature of small-airway obstruction in chronic obstructive pulmonary disease. N Engl J Med 2004;350(26):2645-53.

20. Qin B, Ma N, Tang Q, et al. Neutrophil to lymphocyte ratio (NLR) and platelet to lymphocyte ratio (PLR) were useful markers in assessment of inflammatory response and disease activity in SLE patients. Mod Rheumatol 2016;26(3):372-6.

21. Ozgonul C, Sertoglu E. Accurate use of neutrophil/lymphocyte ratio in patients with age-related macular degeneration. Ocul Immunol Inflamm 2016;24 (3):359-60.

22. Günay E, Sarınç Ulaşlı S, Akar O, Ahsen A, Günay S, Koyuncu T, Unlü M Neutrophil-to-lymphocyte ratio in chronic obstructive pulmonary disease:a retrospective study. Inflammation 2014;37(2):374-80.

23. Lee SJ, Lee HR, Lee TW, et al. Usefulness of neutrophil to lymphocyte ratio in patients with chronic obstructive pulmonary disease:a prospective observational study. Korean J Intern Med 2016;31:891-8.

24. Gan WQ, Man SF, Senthilselvan A, Sin DD. Association between chronic obstructive pulmonary disease and systemic inflammation:a systematic review and a meta-analysis. Thorax 2004;59:574-80.

25. Hurst JR, Donaldson GC, Perera WR, et al. Use of plasma biomarkers at exacerbation of chronic obstructive pulmonary disease. Am J Respir Crit Care Med 2006;174:867-74.

26. Taylan M, Demir M, Kaya H, et al. Alterations of the neutrophil-lymphocyte ratio during the period of stable and acute exacerbation of chronic obstructive pulmonary disease patients. Clin Respir J 2017;11(3):311-7.

27. Yang W, Wang $X$, Zhang W, et al. Neutrophil-lymphocyte ratio and platelet- lymphocyte ratio are 2 new inflammatory markers associated with pulmonary involvement and disease activity in patients with dermatomyositis. Clin Chim Acta 2017;465:11-6.

28. Maclay JD, McAllister DA, Johnston S, et al. Increased platelet activation in patients with stable and acute exacerbation of COPD. Thorax 2011;66(9):769-74.

29. Yao CY, Liu XL, Tang Z. Prognostic role of neutrophil-lymphocyte ratio and platelet-lymphocyte ratio for hospital mortality in patients with AECOPD. Int J COPD 2017;12:2285-90.

30. Epidemiologic and methodologic problems in determining nutritional status of older persons. Proceedings of a conference. Albuquerque, New Mexico, October 19-21, 1988. Am J Clin Nutr 1989;50(5 Suppl):1121-35.

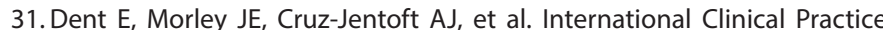
Guidelines for Sarcopenia (ICFSR):Screening, Diagnosis and Management. J Nutr Health Aging 2018;22(10):1148-61.

32. Schols AM, Buurman WA, Staalvan den Brekel AJ, Dentener MA, Wouters EF. Evidence for a relation between metabolic derangements and increased levels of inflammatory mediators in a subgroup of patients with chronic obstructive pulmonary disease. Thorax 1996;51(8):819-24.

33. Zuckerman J, Ades M, Mullie L, et al. Psoas muscle area and length of stay in older adults undergoing cardiac operations. Ann Thorac Surg 2017;103(5):1498-504.

34. Marquis K, Debigare R, Lacasse $Y$, et al. Midthigh muscle cross-sectional area is a better predictor of mortality than body mass index in patients with chronic obstructive pulmonary disease. Am J Respir Crit Care Med 2002;166(6):809-13. 
35. Wagner PD. Possible mechanisms underlying the development of cachexia in COPD. Eur Respir J 2008;31(3):492-501.

36. Byun MK, Cho NE, Chang J, Ahn CM, Kim HJ. Sarcopenia correlates with systemic inflammation in COPD. Int J COPD 2017;12:669-75.

37. Maltais F, Decramer M, Casaburi R, et al. An official American Thoracic Society/European Respiratory Society statement:update on limb muscle dysfunction in chronic obstructive pulmonary disease. Am J Respir Crit Care Med 2014;189:e15-e62.

38. Celli BR, Locantore N, Tal-Singer R, et al. Emphysema and extrapulmonary tissue loss in COPD:a multi-organ loss of tissue phenotype. Eur Respir J 2018;51:1702146.

39. Spruit MA, Gosselink R, Troosters T, et al. Muscle force during an acute exacerbation in hospitalised patients with COPD and its relationship with CXCL8 and IGF-I. Thorax 2003;58:752-6.

40. Limpawattana $P$, Inthasuwan $P$, Putraveephong $S$, et al. Sarcopenia in chronic obstructive pulmonary disease:a study of prevalence and associated factors in the Southeast Asian population. Chronic Respir Dis 2018;15:250-7.

41. Lin J, Zhang W, Huang $Y$, et al. Sarcopenia is associated with the neutrophil/lymphocyte and platelet/lymphocyte ratios in operable gastric cancer patients:a prospective study. Cancer Management and Research 2018;10:4935-44.

42. Feliciano EMC, Kroenke CH, Meyerhardt JA, et al. Association of Systemic Inflammation and Sarcopenia With Survival in Nonmetastatic Colorectal Cancer:Results From the C SCANS Study. JAMA Oncol 2017;3(12):e172319.

43. Jones PW, Agusti AG. Outcomes and markers in the assessment of chronic obstructive pulmonary disease. Eur Respir J 2006;27(4):822-32.

44. Nishimura K, Izumi T, Tsukino M, Oga T. Dyspnea is a better predictor of 5 -year survival than airway obstruction in patients with COPD. Chest 2002;121(5):1434-40. 